\title{
A Earthquake Damage Prediction System in Langfang Based on ArcGIS
}

\author{
Pan $\mathrm{Li}^{1,2, *}$ and Huang Meng ${ }^{2}$ \\ ${ }^{1}$ College of Computer Science and Technology, Jilin University, Changchun, Jilin, 130012, China; ${ }^{2}$ Department of Dis- \\ aster Information Engineering, Institute of Disaster Prevention, Sanhe, Hebei, 065201, China
}

\begin{abstract}
In order to minimize the loss of disasters on urban earthquake damage prediction research is of great significance. This paper, establishment of a data management system based on ArcGIS +Visual Studio. NET platform is an important work of the project, design and development of Langfang City earthquake damage prediction system. Firstly, the overall system framework, then introduce the system to have the document management, Map management, information queries, spatial analysis and other basic functions of the spatial database to establish and thematic map production management, a key link in detail. Finally, through the practical application of Langfang City earthquake damage prediction play a very good decision support role, while the region of space results data for effective organization and management.
\end{abstract}

Keywords: ArcGIS, Earthquake damage prediction, spatial database.

\section{INTRODUCTION}

With the rapid development of cities, population size and scale increasing wealth, the facilities of the city is more complex, keeps the city underground space to the ground vertical development, therefore, the same magnitude of urban earthquake disaster loss is often more serious than in rural areas, even of a region or a country's economic development, political situation and social activities have a significant impact. According to the seismic intensity zoning map in China, is located in the seismic intensity VIII and VII degrees above accounted for $46 \%$ of the total number of Chinese cities, the cities in which more than 1 million people in the big city accounted for $70 \%$. In the vast high intensity zone to nearly 900 million the life of the population. So, to do a good job of protecting against and mitigating earthquake disasters city is necessary [1-3].

This study in order to identify the seismic geological disasters in the distribution and the degree of risk within the planning area of Langfang City, buildings and infrastructure, the basic situation (including spatial distribution, type of structure, seismic design situation, working status) based on, according to the earthquake basic engineering principles, and application of GIS techniques, set different intensity ground motions, make a prediction on urban earthquake disaster severity and spatial distribution, to find out the existing urban earthquake disaster prevention capability to identify earthquake weaknesses and key aspect of the assessment of potential earthquake damage and casualties, for the relevant policy departments taken in advance of earthquake disaster reduction measures.

\section{EARTHQUAKE DAMAGE PREDICTION PRIN- CIPLE}

\subsection{Building Earthquake Damage Factor Method}

Earthquake damage factor method is a method of damage prediction of building experience. Its core idea is compiled during the earthquake damage to buildings have a significant impact on a number of factors, and its numerical value, the size of the numerical to reflect these factors the effects of earthquake damage to buildings in the end [4-7]. In this paper, with the help of nine main influence factors, respectively, the standard, field environment, the field intensity category, type of structure, layer number and level of building s, rules, and use conditions, and the influence factors of the numerical value is called seismic damage factor.

\subsection{Road Earthquake Damage Prediction}

Based on the experience of the road damage prediction method using analytic hierarchy process (AHP) [8, 9]. AHP method is through the various factors of complex problems into interconnected orderly level, streamline, according to the structure of a certain objective reality of subjective judgment (mainly is the comparison of the two) the expert opinion and analysis of the objective judgment result directly and effectively combined with the importance of a two level elements compared to quantitative description. Then, by using mathematical method to calculate reflect elements at each level the value of the relative importance of the order through all levels between the total sorts of calculate the relative weight of all the elements and sorting.

Concrete steps to establish the hierarchical model is as follows: the establishment of a hierarchical model; construct comparative matrix; computing the weight vector and do consistency check; calculate the evaluation results. According to the requirements of the Analytic Hierarchy Process, the process of building the road damage forecasting model are as follows: After the analysis and comparison, to determine the damages based on the experience of foundation failure, earthquake intensity, landforms, roadbed type, subgrade elevation, technical grade, driveways features, site classification, road type and time to build a total of 10 factors as the impact of road embankment road damage factor, sorted by the importance of each factor, construct comparative matrix (comparison matrix constructed here by the consistency test, with strict consistency); according to contrast weight vector matrix calculation to determine the weight of 
each factor weights, with damage to quantify value as a quantitative measure of the value of each factor.

\section{EARTHQUAKE DAMAGE PREDICTION SYS- TEM DESIGN}

\subsection{System Structure Design}

The system is composed of database management system, function modules, and user graphical interface. The database includes spatial database and attribute database. Each function module adopts the component GIS technique that is the Visual C\# + ArcGIS Engine [10]. The system also uses AE components such as MapControl, PageLayoutContro1, TocContro1 and Toolbar Control to accomplish the basic functions of map view, roaming, scaling, key element searching and map print. The user interface is designed by Visual C\#. System structure is shown as Fig. (1).

\subsection{Data Sources}

Basic geographic information of the city (the city's largescale topographic map including buildings, streets, topography and surface features information, etc.), distribution of professional information (urban earthquake disaster risk and its degree of influence of urban earthquake disaster, the comprehensive zoning of urban earthquake disaster, earth quake devastating effects of disasters on building vulnerability analysis, vulnerability analysis of various urban lifeline engineering, a variety of secondary disasters, economic losses and casualties, the specific strategies and decision support analysis of the disaster in different disaster situations) and the city socio-economic planning and development information (population distribution, various economic indicators and parameters), the establishment of the basis of detailed city, specializing in database.

\subsection{Spatial Database Design and Establishment}

Analysis of data sources, based on earthquake emergency response collaboration disaster database specification combined with Langfang earthquake damage prediction project finished review draft of the data format requirements, standardizing the data, the establishment of urban earthquake damage prediction system space database. Layers are the basic unit of data storage in the spatial database, by the established topology of the spatial characteristics and one-toone correspondence with every feature of the property. Each layer to form a subdirectory for each directory contains several to dozens of documents.

Using ArcSDE to manage the spatial database, the underlying relational database is of Geodatabase. Because a lot of information and data stored in the form of information, and not with the spatial data is associated. So I take the way of the attribute data and meta-data stored separately from the interconnection of the properties and meta-data can be achieved through the definition of the corresponding foreign key way. Both the bottom of relying on the relational database of Geodatabase, spatial data is to manage ArcSDE data engine, and attribute data directly through Geodatabase operation is to use Geodatabase the stability management. The ArcSDE Geodatabase database is table space storage mapping, so the property metadata of peer review in the same bindery operating efficiency is high, the back-end database system quick reaction, the front page of the response speed is relatively faster.

\section{MAIN FUNCTIONS OF THE SYSTEM}

\subsection{Document management function}

This module implements the functions to open, save, save as, recently opened map document, and shape file load function. The system provides conversion functions for Ex-

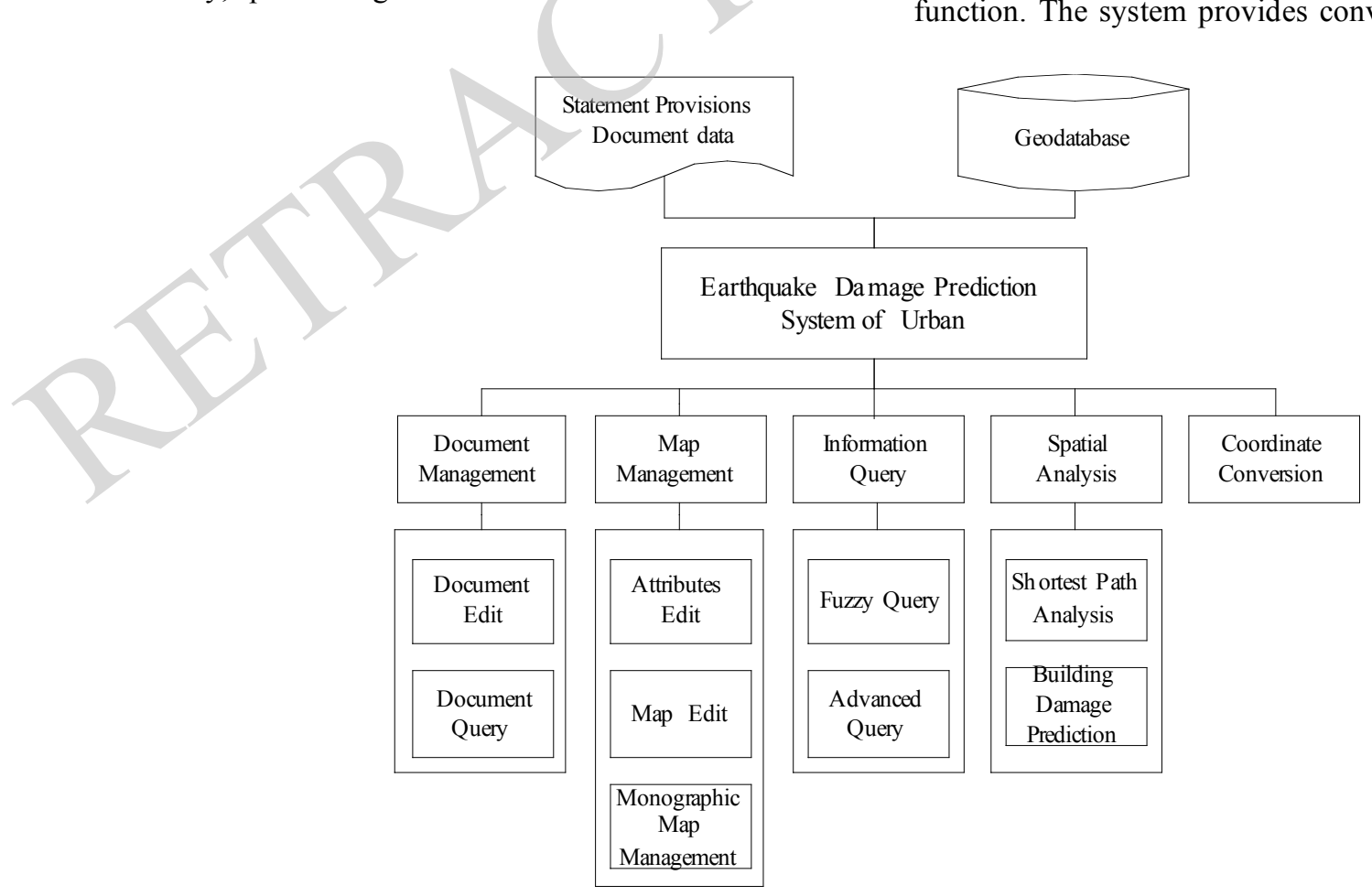

Fig. (1). Frame diagram of earthquake damage prediction system. 
cel and Word file import and export, to facilitate data input and output, save manpower, save time. Compliance reports and other documents, you can query, display, edit and other functions.

\subsection{Map Management Function}

Basic map operation: This system has the map to zoom and move the map display, map roaming, multiple layers of alternating display; to open, add the appropriate layer, and the save and save as functions of the Figure layer to delete, edit, and can manually set the layer to be displayed or hidden data; line adjustment map, you can also add and delete lines; Hawkeye map to determine the specific location in the map on the watchdata is more targeted.

Attribute editing function: Each layer corresponding to the attribute table can be edited, the contents of the attribute table can also be exported to excel in the form, to excel sheet guide belonging to the table shp file. Attribute information can display and query. Property list functions can be selected properties of the layers in the bottom of the screen in tabular form to list them all. For example: you can view a street in the attribute information: street names, bus routes, streets, hospitals and schools distribution.

Monographic map production and management functions: The thematic map is a powerful way for analysis and performance data through the use of thematic maps data graphically, so that the data reflected on the map in a more intuitive form.

The system provides several types of thematic map data for users. The user can produce their own thematic maps, the system has the function to insert the contents of the title, legend, scale and compass to the thematic maps. Can customize the drawing, use the tool to draw the corresponding circle, ellipse, from the shape, multilateral Figure, curve, line segments, can also use the brush to draw the graphics, you can also use the eraser tool to delete the painted graphics, brushes can set the color thickness. The system can open, add, edit, modify, delete the operation of the selected thematic maps.

Point, line and area three types of special symbols, according to their qualitative and quantitative classification, respectively, for symbol design. The symbol for the qualitative data, drawing static and geographic base map layer overlay; quantitative data symbols can be connected with the back-end database to achieve a dynamic real-time rendering.

Properties of spatial objects in the table in the database, each spatial characteristics corresponding attributes (parameters) is called a record (record), the general performance of the row in the table.Each attribute, the corresponding one of the tables in the database, known as a (item).A special class of characteristics of each thematic layer only for a specific professional content storage, listed in Table $\mathbf{1}$, the system 17 thematic layers.

Measure Distance function: On the graph can be measured the actual distance between two values, can also measure the pairwise distance of the additive in the multi-point.

Buffer analysis: It can the elements of a map as the center, to a certain distance radius buffer analysis, but also lists the properties of each element.
Table 1. Coverage in the system.

\begin{tabular}{|c|c|}
\hline Number & Contents \\
\hline 1 & Ancient river maps for urban planning area \\
\hline 2 & $\begin{array}{l}\text { City hedge evacuate the workplace investigation and } \\
\text { evaluation of thematic maps }\end{array}$ \\
\hline 3 & Urban earthquake hazard assessment of thematic maps \\
\hline 4 & $\begin{array}{l}\text { City power system to earthquake damage prediction of } \\
\text { thematic maps }\end{array}$ \\
\hline 5 & $\begin{array}{l}\text { Urban drainage system in earthquake damage prediction of } \\
\text { thematic maps }\end{array}$ \\
\hline 6 & Urban Planning and Regional Road status maps \\
\hline 7 & Landform types of urban planning area zoning maps \\
\hline 8 & $\begin{array}{l}\text { Groundwater depth zoning maps of the urban planning } \\
\text { area }\end{array}$ \\
\hline 9 & $\begin{array}{l}\text { Urban planning area ground motion parameter zoning } \\
\text { maps }\end{array}$ \\
\hline 10 & $\begin{array}{l}\text { Engineering geological zoning maps of the urban planning } \\
\text { area }\end{array}$ \\
\hline 11 & Urban planning area saturated sand thickness zoning maps \\
\hline 12 & Urban planning area saturated sand thickness zoning maps \\
\hline 13 & $\begin{array}{l}\text { Urban transport system earthquake damage prediction } \\
\text { network of thematic maps }\end{array}$ \\
\hline 14 & $\begin{array}{l}\text { City gas system and thermal system to earthquake damage } \\
\text { prediction of thematic maps }\end{array}$ \\
\hline 15 & $\begin{array}{l}\text { Urban population and economic loss assessment of the- } \\
\text { matic maps }\end{array}$ \\
\hline 16 & $\begin{array}{l}\text { The city has considered building damage prediction un- } \\
\text { dermine the thematic maps }\end{array}$ \\
\hline 17 & The drilling location of the urban planning area maps \\
\hline
\end{tabular}

\subsection{Data Query Function}

By looking for the tools can be according to the user in the query window, enter the query layer properties of strings, lists all the information distribution to meet this criteria, the corresponding fuzzy and precise query. Enter the corresponding name on the map to display the corresponding name entered, you can also query by selecting the appropriate conditions, can also be displayed on the map.

Custom queries can be applied to SQL structured query language expression map query results will list all eligible spatial characteristics, as well as further analysis of these information points.

\subsection{Spatial Analysis Function}

Earthquake damage prediction: means a national or a regional seismic hazard analysis, seismic zoning or zoning, engineering and construction vulnerability analysis based on the casualties of the staff of a future time may be caused by 


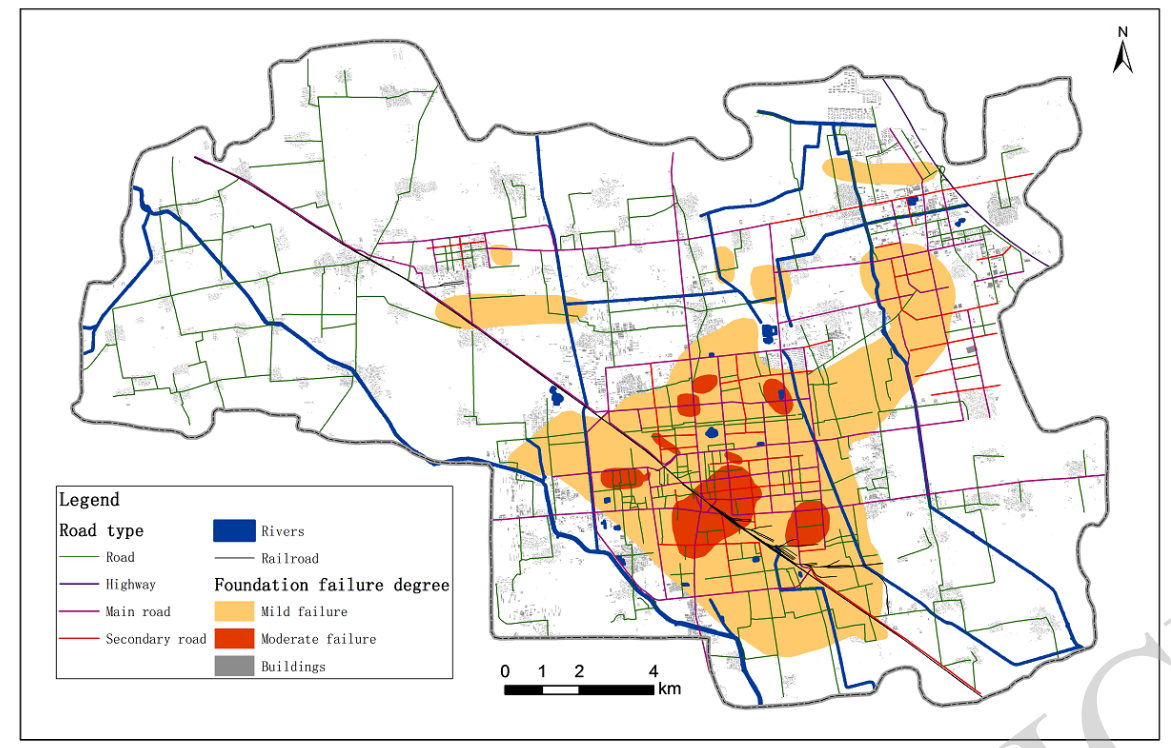

Fig. (2). District Langfang Simulation Predicted the Extent of the Foundation Failure under Figure VII Earthquake.

the earthquake, the building (structure) buildings and facilities destroyed, estimates of economic losses and their distribution.

Shortest path analysis: to identify the two layers, click the button to display the distance between two points, and line color of the distance between two points free exchange.

\section{APPLICATION EXAMPLE}

The project work on the basis of existing work, earthquake geological hazards, according to research distribution and the degree of risk, buildings and infrastructure (including the spatial distribution of the type of structure, seismic design situation, working status, to establish GIS spatial database, according to the basic principle of earthquake Engineering and GIS spatial analysis of the application model and make predictions on urban earthquake disaster severity and spatial distribution, to find out the existing urban earthquake disaster prevention capability to identify earthquake weaknesses and the key link, the assessment may earthquake losses and casualties, the earthquake disaster reduction measures taken in advance for the decision-making departments.

The Langfang earthquake damage prediction system Fig. (2) is based on the integration of advanced GIS technology and emergency information resources, and emergency support system combining software and hardware. In a unified geographic framework on the basis of the command information of various emergency platform 2D visualization display, integrated query and analysis, and to provide efficient decision support capabilities. It has a risk assessment, monitoring and control, prediction and warning, intelligent decision-making, an integrated and coordinated emergency response and summary evaluation functions.

\section{CONCLUSION}

Earthquake prediction assessment is a complex, multidisciplinary problem. China's rapid reaction capability of cities to respond to natural disasters, to enhance the overall decision-making and command capabilities, technical support and disposal efficiency, alleviating the threat of disasters on the city, is very important. Langfang City earthquake damage prediction system through the design and development of the research done and the results obtained experience has shown that seismic damage prediction is related to many uncertain factors, how to consider a number of key factors to improve the prediction function to give a more reasonable the forecast result is a in-depth study of scientific problems.

\section{CONFLICT OF INTEREST}

The authors confirm that this article content has no conflicts of interest.

\section{ACKNOWLEDGEMENTS}

This work has been supported by a donation from Special Fund of Fundamental Scientific Research Business Expense for Higher School of Central Government (Projects for creation teams) (ZY20110102). We would like to thank many friends and colleagues whose previous work contributed indirectly to this paper.

\section{REFERENCES}

[1] C. Guoxing, and J. Dandan, "Seismic damage and behavior analysis of earth dams during the 2008 Wenchuan earthquake, China," Engineering Geology. Holland, vol. 180, pp. 99-129, 2014.

[2] A. Abo-El-Ezz, and N. Marie-José, "Assessment of earthquakeinduced damage in Quebec city, Canada," International Journal of Disaster Risk Reduction. vol. 29, pp. 38-44, 2014.

[3] E. Florido, and F. Martínez-Álvarez, "Detecting precursory patterns to enhance earthquake prediction in Chile," Computers \& Geosciences. vol. 76, pp. 112-120, 2015.

[4] J. Santos-reyes, T. Gouzeva, and G. Santos-reyes, "Earthquake risk perception and mexico city's public safety, "Procedia Engineering. vol. 84, pp. 662-671, 2014.

[5] J. Gao, F. Qimin, and S. Mo, "Urban earthquake disaster prediction and its general program research of information management," World Earthquake Engineering. China, vol. 21, pp. 75-08, 2005. 
[6] Y. Guan, Q. Qimin, and H. Ma, "The database design of urban earthquake emergency command decision support software," World Earthquake Engineering. China, vol. 21, pp. 77-81, 2005.

[7] Z. Haoyao, S. Jinbao, and Z. Shichen, "Principal component analysis method applying to earthquake-damaged reservoir's comprehensive evaluation," In: Procedia Engineering, vol. 28, pp. 548554, 2005.

[8] H. Meng, and Z. Lei, "Earthquake damage prediction system of buildings group based on damage factors method,"ITMS 2013, Zhenzhou, vol. 341, pp. 1496-1499, 2005.
[9] G. Youhai, F. Qimin, and W. Yuntao, “ Design and development on urban earthquake emergency countermeasure spatial decision support system," In: Proceedings of the International Symposium on Safety Science and Technology, Changsha, vol. 24, pp. 513-517, 2006.

[10] M. Hashemi, and A. Asghar, " A GIS-based earthquake damage assessment and settlement methodology," Soil Dynamics and Earthquake Engineering. vol. 31, pp. 1607-1617, 2011.

Received: January 09, 2015

Revised: April 11, 2015

Accepted: May12, 2015

(C) Li and Meng; Licensee Bentham Open.

This is an open access article licensed under the terms of the (https://creativecommons.org/licenses/by/4.0/legalcode), which permits unrestricted, noncommercial use, distribution and reproduction in any medium, provided the work is properly cited. 